\title{
Strategic weight manipulation in multiple attribute decision
}

\author{
making ${ }^{1}$ \\ Yucheng Dong ${ }^{\mathrm{a}}$, Yating Liu ${ }^{\mathrm{a}}$, Haiming Liang ${ }^{\mathrm{a}}$, Francisco Chiclana ${ }^{\mathrm{b}}$, Enrique Herrera-Viedma ${ }^{\mathrm{c}, \mathrm{d}}$ \\ a. Business School, Sichuan University, Chengdu, 610065, China \\ b. Centre for Computational Intelligence, Faculty of Technology, De Montfort University, \\ Leicester, UK \\ c. Department of Computer Science and Artificial Intelligence, University of Granada, Granada, \\ Spain \\ d. Department of Electrical and Computer Engineering, Faculty of Engineering, King Abdulaziz \\ University, Jeddah, Saudi Arabia
}

\begin{abstract}
In some real-world multiple attribute decision making (MADM) problems, a decision maker can strategically set attribute weights to obtain her/his desired ranking of alternatives, which is called the strategic weight manipulation of the MADM. In this paper, we define the concept of the ranking range of an alternative in the MADM, and propose a series of mixed 0-1 linear programming models (MLPMs) to show the process of designing a strategic attribute weight vector. Then, we reveal the conditions to manipulate a strategic attribute weight based on the ranking range and the proposed MLPMs. Finally, a numerical example with real background is used to demonstrate the validity of our models, and simulation experiments are presented to show the better performance of the ordered weighted averaging operator than the weighted averaging operator in defending against the strategic weight manipulation of the MADM problems.
\end{abstract}

Keywords: multiple attribute decision making, strategic weight manipulation, the ordered weighted averaging operator, ranking

\section{Introduction}

Multiple attribute decision making (MADM) refers to the problem of ranking alternatives based on the evaluation information of alternatives associated with multiple attributes $[9,10,16,25,31]$. The MADM has been widely used in 
engineering, technology, economy, management, and military, and many other fields $[12,15,18,22,40]$.

The attribute weights play an important role in MADM problems. In the existing literature, there are several approaches to obtain the attribute weights that can be classified into three categories: the subjective approach, the objective approach and the integrated approach.

(1) The subjective approach determines the attribute weights in terms of the decision maker's preference information on attributes $[2,8,28]$. Doyle et al. [8], for example, proposed direct rating and point allocation methods. Meanwhile, several ordinal ranking methods are investigated in [1, 26, 29], and recently, Danielson et al. [5] provided an augmenting ordinal method for obtaining attribute weights.

(2) The objective approach determines the weights of attributes using objective decision matrix information. This approach includes the entropy method [40], the TOPSIS-based method $[20,41]$ and some mathematical programming based methods (e.g. [3]).

(3) The integrated approach determines the weights of attributes using both decision makers' subjective information and objective decision matrix information. Within these approaches, Cook and Kress [4] proposed the preference-aggregation model based on the use of the Data Envelopment Analysis. Moreover, Fan et al. [11], Horsky and Rao [14] and Pekelman and Sen [23] constructed some optimizationbased models to assess the attribute weights based on the use of decision maker's preference information on alternatives.

Generally, in a process of decision making, the decision makers may express their opinions dishonestly to obtain their own interests, which is referred to as strategic manipulation or non-cooperative behavior. The strategic manipulation has been analyzed in-depth with respect to the aggregation function $[24,37,38]$, the consensus reaching process $[6,13,30]$, and also in large-scale group decision making $[7,21,36]$. It is natural to assume that the process of setting attribute weights in MADM problems is not immune to strategic manipulations, and that a decision maker may strategically set attribute weights in order to obtain her/his desired 
ranking of the alternative(s). In this study we refer to this kind of strategic manipulations in MADM as the strategic weight manipulation problem.

As mentioned above, there exist different (subjective, objective and integrated) approaches to attribute weights setting. Within these approaches, the decision maker is assumed to be honest, and aims to obtain "best" attribute weights to get a ranking of alternatives. We need to highlight that this paper focuses on the strategic weight manipulation problem in which the decision maker is assumed not to be honest, and she/he aims to strategically set attribute weights to obtain her/his desired ranking of the alternatives.

Although there exist numerous methods to set attribute weights, these approaches do not always consider the general theoretical framework that governs the strategic weight manipulation.

In order to fill this gap, several research challenges are proposed for analysis in this paper:

(1) How to determine the range of the ranking of alternatives when a decision maker strategically set the attribute weights in MADM problems.

(2) When a decision maker wishes to manipulate the ranking of alternatives with a predetermined purpose, how to design a strategic weight vector to achieve this purpose.

(3) How to analyze the performances of two different average operators, the weighted averaging (WA) and the ordered weighted averaging (OWA), in defending against strategic weight manipulation in MADM problems.

In order to do so, the rest of this paper is organized as follows. Section 2 provides the basic knowledge regarding MADM problems and introduces the proposed strategic weight manipulation problem. Then, in Section 3, mixed 0-1 linear programming models are proposed to obtain the ranking range of an alternative under the conditions that the attribute weights being strategically changed, and several desired properties of the ranking range of alternatives are studies. In section 4 , mixed 0-1 linear programming models are used to analyze how to design a strategic weight vector to manipulate the ranking of alternative(s) to achieve a desired purpose. 
Section 5 presents a numerical example to illustrate the proposed models, and simulation experiments are presented to compare the performances of the WA and OWA [32, 39] operators in defending against strategic weight manipulation in MADM problems. Concluding remarks and future research agenda are provided in Section 6.

\section{Background}

This section introduces the MADM problem and the concept of ranking range of an alternative, which will provide a basis to study the strategic weight manipulation problem in MADM.

\subsection{MADM problem}

Let $X=\left\{x_{1}, x_{2}, \ldots, x_{n}\right\}$ be the set of alternatives, $A=\left\{a_{1}, a_{2}, \ldots, a_{m}\right\}$ the set of predefined attributes, and $w=\left(w_{1}, w_{2}, \ldots, w_{m}\right)$ the associated weight vector of the attributes, such that $w_{j} \geq 0$ and $\sum_{j=1}^{m} w_{j}=1$. Let $V=\left[v_{i j}\right]_{n \times m}$ be the decision matrix given by the decision maker, where $v_{i j}$ denotes the preference value for the alternative $x_{i} \in X$ with respect to the attribute $a_{j} \in A$, representing how well alternative $x_{i}$ verifies attribute $a_{j}$.

Generally, the resolution process of MADM problems includes three steps:

(1) Normalization of the decision matrix

In MADM problems, attributes are classified into two categories: benefit attributes and cost attributes. The decision maker's decision matrix $V=\left[v_{i j}\right]_{n \times m}$ needs to be normalized into a corresponding standardized individual's decision matrix $\bar{V}=\left[\bar{v}_{i j}\right]_{n \times m}$, where

$$
\bar{v}_{i j}=\frac{v_{i j}-\min _{i}\left(v_{i j}\right)}{\max _{i}\left(v_{i j}\right)-\min _{i}\left(v_{i j}\right)}
$$

if $a_{j} \in A$ is a benefit attribute, and

$$
\bar{v}_{i j}=\frac{\max _{i}\left(v_{i j}\right)-v_{i j}}{\max _{i}\left(v_{i j}\right)-\min _{i}\left(v_{i j}\right)}
$$

if $a_{j} \in A$ is a cost attribute.

(2) Aggregation of the standardized decision matrix 
Let $D\left(x_{i}\right)$ be the decision evaluation value of the alternative $x_{i}$, which is obtained by aggregating its associated attribute preference values using Eq. (3) and an appropriate aggregation operator $F$ :

$$
D\left(x_{i}\right)=F\left(\bar{v}_{i 1}, \bar{v}_{i 2}, \ldots, \bar{v}_{i m}\right)
$$

In MADM problems, the aggregation operators frequently used are the WA operator and the OWA operator [32, 39].

When $F$ is a WA operator with an associated weight vector $w=\left(w_{1}, w_{2}, \ldots, w_{m}\right)$, Eq. (3) can be rewritten as follows:

$$
D\left(x_{i}\right)=W A_{w}\left(\bar{v}_{i 1}, \bar{v}_{i 2}, \ldots, \bar{v}_{i m}\right)=\sum_{j=1}^{m} w_{j} \bar{v}_{i j}
$$

While, when $F$ is a OWA operator with an associated weight vector $w=$ $\left(w_{1}, w_{2}, \ldots, w_{m}\right)$, Eq. (3) can be rewritten as follows:

$$
D\left(x_{i}\right)=O W A_{w}\left(\bar{v}_{i(1)}, \bar{v}_{i(2)}, \ldots, \bar{v}_{i(m)}\right)=\sum_{j=1}^{m} w_{j} \bar{v}_{i(j)}
$$

where $\bar{v}_{i(j)}$ is the $j$ th largest value in $\left\{\bar{v}_{i 1}, \bar{v}_{i 2}, \ldots, \bar{v}_{i m}\right\}$.

(3) Ranking of alternatives

Let $Q_{k}=\left\{x_{i} \mid D\left(x_{i}\right)>D\left(x_{k}\right), \quad i=1,2, \ldots, n\right\}$ be the set of the alternatives whose decision evaluation value is greater than that of the alternative $x_{k}$, and $\left|Q_{k}\right|$ be its cardinality. Clearly, for $Q_{k}$, because $x_{k} \notin Q_{k}$, then alternative $x_{k}$ such that $D\left(x_{k}\right)=\max$ $\left\{D\left(x_{1}\right), \ldots, D\left(x_{n}\right)\right\}$ might verify as well that $\left|Q_{k}\right|=0$, while alternative $x_{j} \notin Q_{j}$, such that $D$ $\left(x_{j}\right)=\min \left\{D\left(x_{1}\right), \ldots, D\left(x_{n}\right)\right\}$ might as well have $\left|Q_{j}\right|=n-1$, and therefore this alternative will be ranked in 1-st and $n$-th positions, i.e., it is justified the following definition of the ranking position of an alternative in terms of $\left|Q_{k}\right|: r_{k}=\left|Q_{k}\right|+1$, i.e.,

$$
r\left(x_{k}\right)=\left|\left\{x_{i} \mid D\left(x_{i}\right)>D\left(x_{k}\right), \quad i=1,2, \ldots, n\right\}\right|+1
$$

Based on the ranking of alternatives, we can easily obtain the following results.
(1) Let $x_{i}>x_{j} \Leftrightarrow r\left(x_{i}\right)<r\left(x_{j}\right)$, then we have $x_{i}>x_{j} \Leftrightarrow D\left(x_{i}\right)>D\left(x_{j}\right)$.
(2) Let $x_{i} \preccurlyeq x_{j} \Leftrightarrow r\left(x_{i}\right) \geq r\left(x_{j}\right)$, then we have $x_{i} \preccurlyeq x_{j} \Leftrightarrow D\left(x_{i}\right) \leq D\left(x_{j}\right)$. 


\subsection{The proposed research problem: Strategic weight manipulation}

Let $r_{w}\left(x_{k}\right)$ be the ranking of alternative $x_{k}$ when setting the associated weight vector of the attributes $w=\left(w_{1}, w_{2}, \ldots, w_{m}\right)$. Clearly, $r_{w}\left(x_{k}\right)$ can change when the weight vector $w=\left(w_{1}, w_{2}, \ldots, w_{m}\right)$ is changed, in other words, the manipulation of the weight vector can lead to a change in the ranking order of the alternatives. The following example clearly illustrates this issue.

Example 1: Assume three alternatives $\left\{x_{1}, x_{2}, x_{3}\right\}$ and four attributes $\left\{a_{1}, a_{2}, a_{3}, a_{4}\right\}$ with the following standardized decision matrix $\bar{V}=\left[\bar{v}_{i j}\right]_{3 \times 4}$ is:

$$
\bar{V}=\left[\begin{array}{cccc}
0.59 & 1 & 0.8 & 0.63 \\
0.6 & 0.8 & 1 & 0.46 \\
1 & 0.5 & 0.4 & 1
\end{array}\right]
$$

Different $w=\left(w_{1}, w_{2}, \ldots, w_{m}\right)$ lead to different rankings $r_{w}(x)=\left\{r_{w}\left(x_{1}\right), r_{w}\left(x_{2}\right), r_{w}\left(x_{3}\right)\right\}$ of the alternatives $X=\left\{x_{1}, x_{2}, x_{3}\right\}$. Indeed,

1) If we set $w=(0.3,0.2,0.1,0.4)$, then we have $r_{w}(x)=\{3,2,1\}$;

2) If we set $w=(0.1,0.45,0.24,0.21)$, then it is $r_{w}(x)=\{1,2,3\}$;

3) While if we set $w=(0.3,0.1,0.5,0.1)$, then $r_{w}(x)=\{2,1,3\}$ is obtained.

Because different attribute weights yield different ranking of alternatives, in this paper, we give the definition of ranking range of an alternative as follows:

Definition 1: In MADM problems, $R\left(x_{k}\right)=\left[r\left(x_{k}\right), \bar{r}\left(x_{k}\right)\right]$ is known as the ranking range of the alternative $x_{k}$, with $\underline{r}\left(x_{k}\right)=\min _{w \in W} r_{w}\left(x_{k}\right)$ and $\bar{r}\left(x_{k}\right)=\max _{w \in W} r_{w}\left(x_{k}\right)$ being the best and worst rankings of alternative $x_{k}$, respectively, and $W=\left\{w=\left(w_{1}, w_{2}, \ldots, w_{m}\right) \mid \sum_{j=1}^{m} w_{j}=1, \quad 0 \leq w_{j} \leq 1\right\}$.

In addition, in this paper, we introduce the concept of attribute ranking and attribute ranking range to analyze the properties of the ranking range of an alternative.

Let $O_{j}\left(x_{k}\right)=\left\{x_{i} \mid \bar{v}_{i j}>\bar{v}_{k j}\right\}(i=1,2, \ldots, n ; j=1,2, \ldots, m)$ be the set of alternatives whose decision evaluation value is greater than that of the alternative $x_{k}$ associated with the attribute $a_{j}$, and $\left|O_{j}\left(x_{k}\right)\right|$ be its cardinality. Let $\bar{O}_{j}\left(x_{k}\right)=\left\{x_{i} \mid \bar{v}_{i j} \leq \bar{v}_{k j}\right\} \quad(i=1,2, \ldots, n$; $j=1,2, \ldots, m)$ be the set of alternatives whose decision evaluation value is not greater than that of the alternative $x_{k}$ associated with the attribute $a_{j}$, and $\left|\bar{O}_{j}\left(x_{k}\right)\right|$ be its 


\section{cardinality.}

Based on the sets $O_{j}\left(x_{k}\right)$ and $\bar{O}_{j}\left(x_{k}\right)$, the concept of attribute ranking and attribute ranking range can be formally presented as follows:

Definition 2: In MADM problems, $c_{j}\left(x_{k}\right)=\left|O_{j}\left(x_{k}\right)\right|+1$, i.e.,

$c_{j}\left(x_{k}\right)=\left|\left\{x_{i} \mid \bar{v}_{i j}>\bar{v}_{k j}\right\}\right|+1, \quad(j=1,2, \ldots, m)$

is the attribute ranking of the alternative $x_{k}$ associated with the attribute $a_{j}$. Then, let $\underline{c}\left(x_{k}\right)=\min _{j} c_{j}\left(x_{k}\right)$ and $\bar{c}\left(x_{k}\right)=\max _{j} c_{j}\left(x_{k}\right), C\left(x_{k}\right)=\left[\underline{c}\left(x_{k}\right), \bar{c}\left(x_{k}\right)\right]$ is the attribute ranking range of the alternative $x_{k}$.

As mentioned above, in MADM problems, a decision maker could strategically set an attribute weight vector to obtain her/his desired ranking of alternative(s), which in this paper is referred to as the strategic weight manipulation in MADM.

In the following, based on the concept of ranking range, we investigate some issues on the strategic weight manipulation of the MADM to deal with the challenges presented in the introduction section.

In order to improve readability, the main notation used in this paper is listed as follows.

$X$ : The set of alternatives;

A: The set of attributes;

$V=\left[v_{i j}\right]_{n \times m}:$ Decision matrix;

$\bar{V}=\left[\bar{v}_{i j}\right]_{n \times m}:$ Standardized decision matrix;

$S$ : The set of attribute weight vectors;

$D\left(x_{i}\right)$ : The evaluation value of the alternative $x_{i}$;

$r_{w}\left(x_{k}\right)$ : The ranking of the alternative $x_{k}$ under the attribute weight vector $w$;

$\underline{r}\left(x_{k}\right)$ : The best ranking of the alternative $x_{k}$;

$\bar{r}\left(x_{k}\right)$ : The worst ranking of the alternative $x_{k}$;

$R\left(x_{k}\right)=\left[r\left(x_{k}\right), \bar{r}\left(x_{k}\right)\right]:$ Ranking range of the alternative $x_{k} ;$

$R_{W A}\left(x_{k}\right)=\left[\underline{r}_{W A}\left(x_{k}\right), \bar{r}_{W A}\left(x_{k}\right)\right]$ : Ranking range under the WA operator;

$R_{\text {OWA }}\left(x_{k}\right)=\left[\underline{r}_{O W A}\left(x_{k}\right), \bar{r}_{\text {OWA }}\left(x_{k}\right)\right]$ : Ranking range under the OWA operator;

$C\left(x_{k}\right)=\left[\underline{c}\left(x_{k}\right), \bar{c}\left(x_{k}\right)\right]:$ Attribute ranking range of the alternative $x_{k}$. 


\section{Ranking range}

The ranking range of an alternative is used to provide the best and worst ranking of the alternative, which is a basis for strategically setting the attribute weights in MADM problems. In this section, we present mixed 0-1 linear programming models to obtain the ranking range of an alternative, and show several desired properties of the ranking range of an alternative.

\subsection{Obtaining the ranking range via a mixed 0-1 linear programming}

Let $y_{i} \in\{0,1\}, M$ a large enough number, and $D\left(x_{i}\right)$ be defined as per Eq. (3). Then, we can easily obtain the following results.

(1) $x_{i}>x_{k}$ if and only if $y_{i}=1$ under the conditions $D\left(x_{i}\right)>D\left(x_{k}\right)-\left(1-y_{i}\right) M$ and $D\left(x_{i}\right) \leq D\left(x_{k}\right)+y_{i} M$

(2) $x_{i} \preccurlyeq x_{k}$ if and only if $y_{i}=0$ under the conditions $D\left(x_{i}\right) \leq D\left(x_{k}\right)+y_{i} M$ and $D\left(x_{i}\right.$ )$>D\left(x_{k}\right)-\left(1-y_{i}\right) M$.

Based on the above results, Theorems 1 and 2 to obtain the ranking range $R\left(x_{k}\right)$ $=\left[r\left(x_{k}\right), \bar{r}\left(x_{k}\right)\right]$ of the alternative $x_{k}$ under the WA and OWA operators are presented.

Theorem 1: Let $R_{W A}\left(x_{k}\right)=\left[\underline{r}_{W A}\left(x_{k}\right), \bar{r}_{W A}\left(x_{k}\right)\right]$ be the ranking range of alternative $x_{k}$ when the WA operator $F$ is used to compute the decision evaluation function as per Eq. (4). Then,

(1) The best ranking of alternative $x_{k}, \underline{r}_{W A}\left(x_{k}\right)$ can be obtained via the mixed 0-1 linear programming models (8)-(13).

$$
\left\{\begin{array}{c}
\underline{r}_{W A}\left(x_{k}\right)=\min \sum_{i=1}^{n} y_{i}+1 \\
\text { s.t. }\left\{\begin{array}{l}
\sum_{j=1}^{m} w_{j} \bar{v}_{i j}>\sum_{j=1}^{m} w_{j} \bar{v}_{k j}-\left(1-y_{i}\right) M, \quad(i=1,2, \ldots, n) \\
\sum_{j=1}^{m} w_{j} \bar{v}_{i j} \leq \sum_{j=1}^{m} w_{j} \bar{v}_{k j}+y_{i} M, \quad(i=1,2, \ldots, n) \\
\sum_{j=1}^{m} w_{j}=1 \\
0 \leq w_{j} \leq 1, \quad(j=1,2, \ldots, m) \\
y_{i}=1 \quad \text { or } \quad 0, \quad(i=1,2, \ldots, n)
\end{array}\right.
\end{array}\right.
$$

(2) In models (8)-(13), replace the objective function (8) by 


$$
\bar{r}_{W A}\left(x_{k}\right)=\max \sum_{i=1}^{n} y_{i}+1
$$

Then, the worst ranking of alternative $x_{k}, \bar{r}_{W A}\left(x_{k}\right)$, can be obtained via the mixed 0-1 linear programming models (9)-(14).

The proof of Theorem 1 is provided in Appendix A.

To simplify the notation, models (8)-(13) and models (9)-(14) are both called $P_{1}$ in this paper.

Theorem 2: Let $R_{O W A}\left(x_{k}\right)=\left[\underline{r}_{O W A}\left(x_{k}\right), \bar{r}_{O W A}\left(x_{k}\right)\right]$ be the ranking range of alternative $x_{k}$ when the OWA operator $F$ is used to compute the decision evaluation function as per Eq. (5). Then,

(1)The best ranking of alternative $x_{k}, \underline{r}_{O W A}\left(x_{k}\right)$ can be obtained via the 0-1 linear programming models (15)-(20).

$$
\begin{aligned}
& \left\{\begin{aligned}
& \underline{r}_{O W A}\left(x_{k}\right)=\min \sum_{i=1}^{n} y_{i}+1 \\
& \text { s.t. }\left\{\begin{array}{l}
\sum_{j=1}^{m} w_{j} \bar{v}_{i(j)}>\sum_{j=1}^{m} w_{j} \bar{v}_{k(j)}-\left(1-y_{i}\right) M, \quad(i=1,2, \ldots, n) \\
\sum_{j=1}^{m} w_{j} \bar{v}_{i(j)} \leq \sum_{j=1}^{m} w_{j} \bar{v}_{k(j)}+y_{i} M, \quad(i=1,2, \ldots, n) \\
\sum_{j=1}^{m} w_{j}=1 \\
0 \leq w_{j} \leq 1, \quad(j=1,2, \ldots, m) \\
y_{i}=1 \quad \text { or } \quad 0, \quad(i=1,2, \ldots, n)
\end{array}\right.
\end{aligned}\right. \\
& \text { (2) In models (15)-(20), replace the objective function (15) by } \\
& \bar{r}_{O W A}\left(x_{k}\right)=\max \sum_{i=1}^{n} y_{i}+1
\end{aligned}
$$

Then, the worst ranking of alternative $x_{k}, \bar{r}_{O W A}\left(x_{k}\right)$, can be obtained via the mixed 0-1 linear programming models (16)-(21).

The proof of Theorem 2 is provided in Appendix A.

To simplify the notation, models (15)-(20) and models (16)-(21) are both called $P_{2}$ in this paper. In both models $P_{1}$ and $P_{2}, w_{j}(j=1,2, \ldots, m)$ and $y_{i}(i=1,2, \ldots, n)$ are decision variables. 


\subsection{Desirable properties of ranking range}

In this subsection, we present some desired properties of the ranking range of the alternatives based on the concept of attribute ranking and attribute ranking range.

Let $\left[\underline{r}_{W A}\left(x_{k}\right), \bar{r}_{W A}\left(x_{k}\right)\right],\left[\underline{r}_{O W A}\left(x_{k}\right), \bar{r}_{O W A}\left(x_{k}\right)\right]$ and $\left[\underline{c}\left(x_{k}\right), \bar{c}\left(x_{k}\right)\right]$ be as defined above. The following properties hold:

Property 1: $\left[c\left(x_{k}\right), \bar{c}\left(x_{k}\right)\right] \subseteq\left[\underline{r}_{W A}\left(x_{k}\right), \bar{r}_{W A}\left(x_{k}\right)\right]$ for any $x_{k} \in X$.

The proof of Property 1 is provided in Appendix A. This property shows that the attribute ranking range of an alternative is contained in the ranking range of the alternative under the WA operator.

Let $O_{I_{k}}\left(x_{k}\right)=\left\{x_{i} \mid \bar{v}_{i j}>\bar{v}_{k j}, j=1,2, \ldots, m\right\}$ be the set of the alternatives whose decision evaluation value is greater than that of the alternative $x_{k}$ for all attributes, and $\left|O_{I_{k}}\left(x_{k}\right)\right|$ be its cardinality. Let $\bar{O}_{I_{k}}\left(x_{k}\right)=\left\{x_{i} \mid \bar{v}_{i j} \leq \bar{v}_{k j}, j=1,2, \ldots, m\right\}$ be the set of alternatives whose decision evaluation value is not greater than that of the alternative $x_{k}$ for all attributes, and $\left|\bar{O}_{I_{k}}\left(x_{k}\right)\right|$ be its cardinality. The following property holds:

Property 2: (i) $\underline{r}_{W A}\left(x_{k}\right) \in\left[\left|O_{I_{k}}\left(x_{k}\right)\right|+1, \underline{c}\left(x_{k}\right)\right]$ and (ii) $\bar{r}_{W A}\left(x_{k}\right) \in\left[\bar{c}\left(x_{k}\right), n-\left|\bar{O}_{I_{k}}\left(x_{k}\right)\right|\right]$.

The proof of Property 2 is provided in Appendix A. This property provides an estimation for the ranking range of the alternative $x_{k}$ under the WA operator. The following examples show that Properties 1 and 2 do not hold in the case of the OWA operator.

Example 2: Assume five alternatives $\left\{x_{1}, x_{2}, x_{3}, x_{4}, x_{5}\right\}$ and four attributes $\left\{a_{1}, a_{2}\right.$, $\left.a_{3}, a_{4}\right\}$ with the following standardized decision matrix $\bar{V}=\left[\bar{v}_{i j}\right]_{5 \times 4}$ is:

$$
\bar{V}=\left[\begin{array}{cccc}
0.95 & 0.9 & 0.73 & 0.66 \\
0.8 & 0.59 & 1 & 0.7 \\
0.8 & 0.9 & 0.65 & 0.65 \\
0.6 & 0.66 & 0.9 & 0.71 \\
0.5 & 0.6 & 0.7 & 0.8
\end{array}\right]
$$

Based on Definition 2,

$$
\left[\underline{c}\left(x_{1}\right), \bar{c}\left(x_{1}\right)\right]=[1,4],\left[\underline{c}\left(x_{2}\right), \bar{c}\left(x_{2}\right)\right]=[1,5],\left[\underline{c}\left(x_{3}\right), \bar{c}\left(x_{3}\right)\right]=[1,5],\left[\underline{c}\left(x_{4}\right), \bar{c}\left(x_{4}\right)\right]=[2,4] \text {, and }
$$
$\left[\underline{c}\left(x_{5}\right), \bar{c}\left(x_{5}\right)\right]=[1,5]$. 
Meanwhile, solving $P_{2}$ using the software package LINGO, we have,

$\left[\underline{r}_{O W A}\left(x_{1}\right), \bar{r}_{O W A}\left(x_{1}\right)\right]=[1,2], \quad\left[\underline{r}_{O W A}\left(x_{2}\right), \bar{r}_{O W A}\left(x_{2}\right)\right]=[1,4], \quad\left[\underline{r}_{O W A}\left(x_{3}\right), \bar{r}_{O W A}\left(x_{3}\right)\right]=[2,4]$, $\left[\underline{r}_{O W A}\left(x_{4}\right), \bar{r}_{O W A}\left(x_{4}\right)\right]=[3,4]$, and $\left[\underline{r}_{O W A}\left(x_{5}\right), \bar{r}_{O W A}\left(x_{5}\right)\right]=[5,5]$.

Then, it is obvious that $\left[\underline{c}\left(x_{k}\right), \bar{c}\left(x_{k}\right)\right] \nsubseteq\left[\underline{r}_{O W A}\left(x_{k}\right), \bar{r}_{\text {OWA }}\left(x_{k}\right)\right](k=1,2,3,4,5)$, which means that Property 1 is not true when the OWA operator is used.

Example 3: Assume three alternatives $\left\{x_{1}, x_{2}, x_{3}\right\}$ and four attributes $\left\{a_{1}, a_{2}, a_{3}, a_{4}\right.$ \} with the following standardized decision matrix $\bar{V}=\left[\bar{v}_{i j}\right]_{3 \times 4}$ is:

$$
\bar{V}=\left[\begin{array}{cccc}
0.59 & 1 & 0.8 & 0.63 \\
0.6 & 0.7 & 0.9 & 0.46 \\
0.8 & 0.5 & 0.4 & 0.6
\end{array}\right]
$$

Based on Definition 2,

$$
\left\{\underline{c}\left(x_{1}\right), \underline{c}\left(x_{2}\right), \underline{c}\left(x_{3}\right)\right\}=\{1,1,1\},
$$

and

$$
\left\{\bar{c}\left(x_{1}\right), \bar{c}\left(x_{2}\right), \bar{c}\left(x_{3}\right)\right\}=\{3,3,3\} .
$$

Meanwhile, we have $\left|O_{I_{1}}\left(x_{1}\right)\right|+1=1,\left|O_{I_{2}}\left(x_{2}\right)\right|+1=1, \quad\left|O_{I_{3}}\left(x_{3}\right)\right|+1=1,3-\mid \bar{O}_{I_{1}}$ $\left(x_{1}\right)|=3,3-| \bar{O}_{I_{2}}\left(x_{2}\right) \mid=3$, and $3-\left|\bar{O}_{I_{3}}\left(x_{3}\right)\right|=3$.

Solving $P_{2}$ with the software package LINGO, we have

$$
\left\{\underline{r}_{\text {OWA }}\left(x_{1}\right), \underline{r}_{\text {OWA }}\left(x_{2}\right), \underline{r}_{\text {OWA }}\left(x_{3}\right)\right\}=\{1,2,3\},
$$

and

$$
\left\{\bar{r}_{\text {OWA }}\left(x_{1}\right), \bar{r}_{\text {OWA }}\left(x_{2}\right), \bar{r}_{\text {OWA }}\left(x_{3}\right)\right\}=\{1,2,3\} \text {. }
$$

Clearly, it is $\underline{r}_{O W A}\left(x_{2}\right) \notin\left[\left|O_{I_{2}}\left(x_{2}\right)\right|+1, \underline{c}\left(x_{2}\right)\right], \underline{r}_{O W A}\left(x_{3}\right) \notin\left[\left|O_{I_{3}}\left(x_{3}\right)\right|+1, \underline{c}\left(x_{3}\right)\right], \bar{r}_{O W A}\left(x_{1}\right)$ $\notin\left[\bar{c}\left(x_{1}\right), 3-\left|\bar{O}_{I_{1}}\left(x_{1}\right)\right|\right]$, and $\bar{r}_{O W A}\left(x_{2}\right) \notin\left[\bar{c}\left(x_{2}\right), 3-\left|\bar{O}_{I_{2}}\left(x_{2}\right)\right|\right]$, and consequently Property 2 does not hold in the case of the OWA operator being used.

\section{Strategic weight manipulation}

In MADM problems, the decision maker can strategically set the attribute weights to obtain her/his desired ranking of the alternative(s). In this section, we continue to use mixed 0-1 linear programming models to set a strategic weight to manipulate the ranking of alternative(s) under different aggregation operators. 
Let $w_{0}=\left(w_{1}^{0}, w_{2}^{0}, \ldots, w_{m}^{0}\right)$ be the objective weight vector of the attributes in a MADM problem. Without loss of generality, the decision maker wishes to manipulate the ranking of the alternatives $\left\{x_{1}, x_{2}, \ldots, x_{l}\right\}$.

Let $w=\left(w_{1}, w_{2}, \ldots, w_{m}\right)$ be the decision maker's strategic weight vector to manipulate the alternatives $\left\{x_{1}, x_{2}, \ldots, x_{l}\right\}$. It is natural that the decision maker wishes to minimize the difference between the objective and strategic weight vector, i.e.,

$$
\min \sum_{j=1}^{m}\left|w_{j}-w_{j}^{0}\right|
$$

Without loss of generality, if the decision maker's desired ranking of the alternatives $\left\{x_{1}, x_{2}, \ldots, x_{l}\right\}$ is $\left\{r^{*}\left(x_{1}\right), r^{*}\left(x_{2}\right), \ldots, r^{*}\left(x_{l}\right)\right\}$, then we have

$$
r_{w}\left(x_{k}\right)=r^{*}\left(x_{k}\right) \quad(k=1,2, \ldots, l)
$$

Based on Eqs. (22) and (23), an optimization-based model to find out the decision maker's strategic weight is presented as follows.

$$
\begin{cases}\min & \sum_{j=1}^{m}\left|w_{j}-w_{j}^{0}\right| \\ \text { s.t. } & r_{w}\left(x_{k}\right)=r^{*}\left(x_{k}\right) \quad(k=1,2, \ldots, l)\end{cases}
$$

In order to obtain the optimum solution to model (24), in the following it is shown that model (24) can be transformed into mixed 0-1 linear programming models.

Lemma 1: Let $F$ be the WA operator as per Eq. (4). If there exists $w^{*}=$ $\left(w_{1}^{*}, w_{2}^{*}, \ldots, w_{m}^{*}\right)$ satisfying the constraint conditions (25)-(30) below

$$
\begin{aligned}
& \left\{\begin{array}{l}
\sum_{j=1}^{m} w_{j}^{*} \bar{v}_{i j}>\sum_{j=1}^{m} w_{j}^{*} \bar{v}_{k j}-\left(1-y_{i k}\right) M, \quad(i=1,2, \ldots, n ; k=1,2, \ldots, l) \\
\sum_{j=1}^{m} w_{j}^{*} \bar{v}_{i j} \leq \sum_{j=1}^{m} w_{j}^{*} \bar{v}_{k j}+y_{i k} M, \quad(i=1,2, \ldots, n ; \quad k=1,2, \ldots, l) \\
\sum_{i=1}^{n} y_{i k}+1=r^{*}\left(x_{k}\right), \quad(i=1,2, \ldots, n ; \quad k=1,2, \ldots, l) \\
\sum_{j=1}^{m} w_{j}^{*}=1 \\
0 \leq w_{j}^{*} \leq 1, \quad(j=1,2, \ldots, m) \\
y_{i k}=1 \quad \text { or } \quad 0, \quad(k=1,2, \ldots, l)
\end{array}\right. \\
& \text { then, } r_{w^{*}}\left(x_{k}\right)=r^{*}\left(x_{k}\right) \quad(k=1,2, \ldots, l) .
\end{aligned}
$$


The proof of Lemma 1 is provided in Appendix A.

Lemma 2: Let $F$ be the OWA operator as per Eq. (5). If there exists $w^{*}=$ $\left(w_{1}^{*}, w_{2}^{*}, \ldots, w_{m}^{*}\right)$ satisfying the constraint conditions (27)-(32) below

$\left\{\begin{array}{l}\sum_{j=1}^{m} w_{j}^{*} \bar{v}_{i(j)}>\sum_{j=1}^{m} w_{j}^{*} \bar{v}_{k(j)}-\left(1-y_{i k}\right) M, \quad(i=1,2, \ldots, n ; k=1,2, \ldots, l) \\ \sum_{j=1}^{m} w_{j}^{*} \bar{v}_{i(j)} \leq \sum_{j=1}^{m} w_{j}^{*} \bar{v}_{k(j)}+y_{i k} M, \quad(i=1,2, \ldots, n ; k=1,2, \ldots, l)\end{array}\right.$

Then, $r_{w^{*}}\left(x_{k}\right)=r^{*}\left(x_{k}\right) \quad(k=1,2, \ldots, l)$.

The proof of Lemma 2 is provided in Appendix A.

Based on Lemmas 1 and 2, Theorem 3 is obtained.

Theorem 3: Let $b_{j}=w_{j}-w_{j}^{0}$ and $g_{j}=\left|w_{j}-w_{j}^{0}\right|$.

(1) Let $F$ be the WA operator as per Eq. (4), model (24) can be equivalently transformed into the following mixed 0-1 linear programming models (33)-(42)

$$
\left\{\begin{array}{l}
\min \sum_{j=1}^{m} g_{j} \\
\text { s.t. }\left\{\begin{array}{l}
\sum_{j=1}^{m} w_{j} \bar{v}_{i j}>\sum_{j=1}^{m} w_{j} \bar{v}_{k j}-\left(1-y_{i k}\right) M, \quad(i=1,2, \ldots, n ; \quad k=1,2, \ldots, l) \\
\sum_{j=1}^{m} w_{j} \bar{v}_{i j} \leq \sum_{j=1}^{m} w_{j} \bar{v}_{k j}+y_{i k} M, \quad(i=1,2, \ldots, n ; \quad k=1,2, \ldots, l) \\
b_{j}=w_{j}-w_{j}^{0}, \quad(j=1,2, \ldots, m) \\
b_{j} \leq g_{j}, \quad(j=1,2, \ldots, m) \\
\sum_{j}^{n} y_{i k}+1=r^{*}\left(x_{k}\right), \quad(k=1,2, \ldots, m) \\
\sum_{i=1}^{m} w_{j}=1 \\
0 \leq w_{j} \leq 1, \quad(j=1,2, \ldots, m) \\
y_{i k}=1 \quad \text { or } \quad 0, \quad(k=1,2, \ldots, l)
\end{array}\right.
\end{array}\right.
$$

(2) In models (33)-(42), replace the constraints (34)-(35) by the constraints (43)(44)

$$
\left\{\begin{array}{l}
\sum_{j=1}^{m} w_{j} \bar{v}_{i(j)}>\sum_{j=1}^{m} w_{j} \bar{v}_{k(j)}-\left(1-y_{i k}\right) M, \quad(i=1,2, \ldots, n ; k=1,2, \ldots, l) \\
\sum_{j=1}^{m} w_{j} \bar{v}_{i(j)} \leq \sum_{j=1}^{m} w_{j} \bar{v}_{k(j)}+y_{i k} M, \quad(i=1,2, \ldots, n ; k=1,2, \ldots, l)
\end{array}\right.
$$


Let $F$ be the OWA operator as per Eq. (5) and model (24) can be equivalently transformed into the mixed 0-1 linear programming models (33), (36)-(44).

\section{The proof of Theorem 3 is provided in Appendix A.}

In this paper, we denote the models (33)-(42) as $P_{3}$, and denote the models (33), (36)-(44) as $P_{4}$. In both models $P_{3}$ and $P_{4}, w_{j}(j=1,2, \ldots, m)$ and $y_{i k}(i=1,2, \ldots, n ; k=1,2, \ldots, l)$ are decision variables.

A decision maker can manipulate a strategic weight to obtain her/his desired ranking of the alternatives $\left\{x_{1}, x_{2}, \ldots, x_{l}\right\}$ if the optimum solution to $P_{3}$ or $P_{4}$ exists. Otherwise, it is not possible to obtain her/his desired ranking of the alternatives by manipulating a strategic weight.

Finally, in this section, the existence of solution to models $P_{3}$ and $P_{4}$ is discussed in Properties 3-5.

Property 3: There exist $\left\{r^{*}\left(x_{1}\right), r^{*}\left(x_{2}\right), \ldots, r^{*}\left(x_{l}\right)\right\}\left(r^{*}\left\{x_{k}\right\} \in\left[\underline{r}\left(x_{k}\right), \bar{r}\left(x_{k}\right)\right], k=1,2, \ldots, l\right)$ that satisfy the following conditions: (a) $r^{*}\left(x_{k}\right) \leq r_{w_{0}}\left(x_{k}\right)$ for any $k \in\{1,2, \ldots, l\}$, and (b) $\exists f \in\{1,2, \ldots, l\}$ such that $r^{*}\left(x_{f}\right)<r_{w_{0}}\left(x_{f}\right)$. Then, models $P_{3}$ and $P_{4}$ have feasible solutions.

The proof of Property 3 is provided in Appendix A.

Property 3 provides the condition under which a decision maker can manipulate a strategic weight to obtain a better ranking for the alternatives $\left\{x_{1}, x_{2}, \ldots, x_{l}\right\}$.

Property 4: Let $r^{*}\left(x_{k}\right)=\underline{r}\left(x_{k}\right)$ for any $k \in\{1,2, \ldots, l\}$. Then, the solution of models $P_{3}$ and $P_{4}$ does not exist under the following two conditions:

(1) there exists $b$ such that $b=\left|\left\{x_{i} \mid \underline{r}\left(x_{i}\right)=\underline{r}\left(x_{k}\right), i=1,2, \ldots, l\right\}\right|$ and $b<l$;

(2) there exists $h \in\{1,2, \ldots, l\}$ such that $\underline{r}\left(x_{k}\right)<\underline{r}\left(x_{h}\right)<\underline{r}\left(x_{k}\right)+b$.

The proof of Property 4 is provided in Appendix A.

Property 4 provides conditions under which a decision maker can not manipulate a strategic weight to obtain her/his desired ranking for the alternatives $\left\{x_{1}, x_{2}, \ldots, x_{l}\right\}$ for both WA and OWA operators.

Property 5: When $l=1$, we have that (1) the optimal solution to $P_{3}$ exists if and only if $\underline{r}_{W A}\left(x_{k}\right) \leq r^{*}\left(x_{k}\right) \leq \bar{r}_{W A}\left(x_{k}\right)$; (2) the optimal solution to $P_{4}$ exists if and only if 
$\underline{r}_{O W A}\left(x_{k}\right) \leq r^{*}\left(x_{k}\right) \leq \bar{r}_{O W A}\left(x_{k}\right)$.

The proof of Property 5 is provided in Appendix A.

Property 5 provides condition that make possible for a decision maker to manipulate a strategic weight to obtain any desired ranking within the ranking range of an alternative.

\section{Numerical analysis and simulation experiments}

In this section, an example with real data (provided in Appendix B) taken from the Academic Ranking of World Universitie (ARWU; http://www.arwu.org /) is used to illustrate how the proposed MADM strategic weight manipulation model works. Moreover, simulation experiments comparing the performances of the WA and OWA operators in defending against strategic weight manipulation are also included.

\subsection{Numerical analysis}

Let us consider 50 Universities taken from ARWU as the set of alternatives $\left\{x_{1}, x_{2}, \ldots, x_{50}\right\}$, and the following 6 attributes $\left\{a_{1}, a_{2}, \ldots, a_{6}\right\}$ to rank them:

$a_{1}$ : Quality of Education (Alumni: Alumni of an institution winning Nobel Prizes and Fields Medals);

$a_{2}$ : Quality of Faculty 1 (Award: Staff of an institution winning Nobel Prizes and Fields Medals);

$a_{3}$ : Quality of Faculty 2 (HiCi: Highly cited researchers in 21 broad subject categories);

$a_{4}:$ Papers published in Nature and Science (N\&S);

$a_{5}$ : Papers indexed in Science Citation Index-expanded and Social Science Citation Index (PUB);

$a_{6}$ : Per capita academic performance of an institution (PCP).

First, the data of the 50 universities over the 6 attributes is normalized into a standardized decision matrix $\bar{V}=\left[\bar{v}_{i j}\right]_{50 \times 6}$. Then, using models $P_{1}$ and $P_{2}$, the ranking range of the alternatives $\left\{x_{1}, x_{2}, \ldots, x_{50}\right\}, R_{W A}$ and $R_{O W A}$, are obtained and listed in Table 1.

Table 1: The ranking range $R_{W A}$ and $R_{O W A}$ for the 50 universities

\begin{tabular}{lllllllll}
\hline$x_{i}$ & $R_{W A}$ & $R_{\text {OWA }}$ & $x_{i}$ & $R_{W A}$ & $R_{\text {OWA }}$ & $x_{i}$ & $R_{W A}$ & $R_{\text {OWA }}$ \\
\hline
\end{tabular}




\begin{tabular}{|c|c|c|c|c|c|c|c|c|}
\hline$x_{1}$ & {$[1,2]$} & {$[1,2]$} & $x_{2}$ & {$[2,12]$} & {$[2,9]$} & $x_{3}$ & {$[2,25]$} & {$[2,8]$} \\
\hline$x_{4}$ & {$[2,12]$} & {$[2,8]$} & $x_{5}$ & {$[2,15]$} & {$[2,5]$} & $x_{6}$ & {$[2,47]$} & {$[4,10]$} \\
\hline$x_{7}$ & {$[1,47]$} & {$[1,10]$} & $x_{8}$ & {$[3,24]$} & {$[6,17]$} & $x_{9}$ & {$[3,42]$} & {$[6,14]$} \\
\hline$x_{10}$ & {$[4,12]$} & {$[5,13]$} & $x_{11}$ & {$[5,19]$} & {$[8,23]$} & $x_{12}$ & {$[6,25]$} & {$[10,22]$} \\
\hline$x_{13}$ & {$[9,27]$} & {$[10,30]$} & $x_{14}$ & {$[5,35]$} & {$[9,29]$} & $x_{15}$ & {$[4,34]$} & {$[10,28]$} \\
\hline$x_{16}$ & {$[8,31]$} & {$[16,25]$} & $x_{17}$ & {$[9,28]$} & {$[11,23]$} & $x_{18}$ & {$[6,32]$} & {$[11,29]$} \\
\hline$x_{19}$ & {$[9,50]$} & {$[13,50]$} & $x_{20}$ & {$[8,34]$} & {$[13,38]$} & $x_{21}$ & {$[8,49]$} & {$[14,43]$} \\
\hline$x_{22}$ & {$[3,50]$} & {$[9,50]$} & $x_{23}$ & {$[13,45]$} & {$[14,43]$} & $x_{24}$ & {$[16,44]$} & {$[18,33]$} \\
\hline$x_{25}$ & {$[3,45]$} & {$[9,45]$} & $x_{26}$ & {$[15,48]$} & {$[19,40]$} & $x_{27}$ & {$[20,48]$} & {$[20,38]$} \\
\hline$x_{28}$ & {$[18,44]$} & {$[18,42]$} & $x_{29}$ & {$[17,40]$} & {$[17,40]$} & $x_{30}$ & {$[15,48]$} & {$[20,41]$} \\
\hline$x_{31}$ & {$[16,50]$} & {$[18,50]$} & $x_{32}$ & {$[20,48]$} & {$[19,49]$} & $x_{33}$ & {$[9,50]$} & {$[22,46]$} \\
\hline$x_{34}$ & {$[20,47]$} & {$[18,48]$} & $x_{35}$ & {$[10,49]$} & {$[21,42]$} & $x_{36}$ & {$[14,50]$} & {$[20,47]$} \\
\hline$x_{37}$ & {$[27,50]$} & {$[28,50]$} & $x_{38}$ & {$[13,50]$} & {$[17,49]$} & $x_{39}$ & {$[24,50]$} & {$[28,50]$} \\
\hline$x_{40}$ & {$[18,50]$} & {$[22,50]$} & $x_{41}$ & {$[17,49]$} & {$[29,50]$} & $x_{42}$ & {$[11,50]$} & {$[21,49]$} \\
\hline$x_{43}$ & {$[32,50]$} & {$[28,50]$} & $x_{44}$ & {$[14,50]$} & {$[19,50]$} & $x_{45}$ & {$[24,50]$} & {$[25,50]$} \\
\hline$x_{46}$ & {$[20,50]$} & {$[27,49]$} & $x_{47}$ & {$[25,50]$} & {$[26,50]$} & $x_{48}$ & {$[16,50]$} & {$[23,50]$} \\
\hline$x_{49}$ & {$[28,50]$} & {$[39,50]$} & $x_{50}$ & {$[30,50]$} & {$[28,50]$} & & & \\
\hline
\end{tabular}

Existing approaches to attribute weights setting $[1-5,8,11,14,20,23,26,28,29$, $40,41]$ assume that decision makers honest, and aim to set attribute weights to get an optimal ranking of alternatives. However, a decision maker might be dishonest, and she/he would aspire to strategically set attribute weights to achieve her/his purpose. Next, based on the data in Table 1, we assume that the decision maker aims to strategically set attribute weights in the Academic Ranking of World Universities, illustrating the use of our model in the MADM strategic weight manipulation.

Let $w_{0}$ be the objective weight vector of attributes, and $r_{0}$ be the ranking of the corresponding alternative(s) under the attribute weight vector $w_{0}$. In the example, we set $w_{0}=(1 / 6,1 / 6,1 / 6,1 / 6,1 / 6,1 / 6)$. We set different manipulated alternatives and the desired rankings of these manipulated alternatives, $r^{*}$. Afterwards, models $P_{3}$ and $P_{4}$ are applied to get the manipulated strategic weight vector $w^{*}$ corresponding to the desired ranking of the manipulated alternatives. For example,

(1) Let $x_{3}$ be the manipulated alternative. Clearly, $r_{0}\left(x_{3}\right)=2$. Meanwhile, the 
desired ranking of alternative $x_{3}$ for the decision maker is set to $r^{*}\left(x_{3}\right)=8$. In other words, the decision maker plans to dishonestly depress the ranking of the university $x_{3}$. Then, let $F$ be the OWA operator as per Eq. (5), $P_{4}$ is used to obtain the strategic weight vector $w^{*}=(0.548,0,0.167,0,0.12,0.273)$ to achieve the above purpose;

(2) Let $\left\{x_{8}, x_{13}, x_{14}, x_{15}\right\}$ be the manipulated alternatives. Clearly, $r_{0}=\{8,13,12,14\}$. Meanwhile, the desired ranking of alternatives $\left\{x_{8}, x_{13}, x_{14}, x_{15}\right\}$ for the decision maker is $r^{*}=\{6,12,10,9\}$. In other words, the decision maker plans to dishonestly improve the ranking of the universities $\left\{x_{8}, x_{13}, x_{14}, x_{15}\right\}$. Then, let $F$ be the WA operator as per Eq. (4), $P_{3}$ is used to obtain the strategic weight vector $w^{*}=(0.37,0.1,0.232,0.308,0.323,0)$ to achieve the targeted ranking;

(3) Let $\left\{x_{9}, x_{10}, x_{11}, x_{12}\right\}$ be the manipulated alternatives. Clearly, $r_{0}=\{9,10,11,13\}$. Meanwhile, the desired ranking of alternatives $\left\{x_{9}, x_{10}, x_{11}, x_{12}\right\}$ for the decision maker is $r^{*}=\{3,4,5,6\}$. In other words, the decision maker plans to dishonestly improve the ranking of the universities $\left\{x_{9}, x_{10}, x_{11}, x_{12}\right\}$. Then, let $F$ be the WA operator as per Eq. (4), $P_{3}$ does not have a solution, which means that it is not possible to strategically set a attribute weight vector to achieve the desired ranking.

Table 2 shows the strategic weight vector $w^{*}$ under different manipulated alternatives and the corresponding desired ranking $r^{*}$.

Table 2: The strategic weight vector $w^{*}$ under different manipulated alternatives and the desired ranking $r^{*}$.

\begin{tabular}{ccccc}
\hline $\begin{array}{c}\text { Manipulated } \\
\text { alternative }\end{array}$ & $F$ & $r_{0}$ & $r^{*}$ & $w^{*}$ \\
\hline$x_{3}$ & WA & 2 & 25 & $(0,0,0,0.05,0,0.995)$ \\
& OWA & 2 & 8 & $(0.548,0,0.167,0,0.12,0.273)$ \\
\hline$x_{6}$ & WA & 7 & 2 & $(0.167,0.457,0,0,0,0.376)$ \\
& OWA & 7 & 4 & $(0.586,0.167,0,0,0.081,0.167)$ \\
$x_{20}$ & WA & 18 & 8 & $(0,0,0.009,0.167,0.748,0.076)$ \\
& OWA & 18 & 13 & $(0,0.029,0.167,0.167,0.471,0.167)$ \\
$\left\{x_{8}, x_{13}, x_{14}, x_{15}\right\}$ & WA & $\{8,13,12,14\}$ & $\{3,9,5,4\}$ & No solution \\
& OWA & $\{8,13,12,14\}$ & $\{6,10,9,11\}$ & No solution
\end{tabular}




\begin{tabular}{ccccc}
\hline & WA & $\{8,13,12,14\}$ & $\{6,12,10,9\}$ & $(0.37,0.1,0.232,0308,0.323,0)$ \\
& OWA & $\{8,13,12,14\}$ & $\{6,13,9,11\}$ & $(0,0,1,0,0,0)$ \\
\hline \multirow{2}{*}{ WA } & $\{9,10,11,13\}$ & $\{3,4,5,6\}$ & No solution \\
& OWA & $\{9,10,11,13\}$ & $\{6,5,8,10\}$ & No solution \\
& WA & $\{9,10,11,13\}$ & $\{17,12,13,15\}$ & $(0.06,0,0.783,0.089,0,0.068)$ \\
& OWA & $\{9,10,11,13\}$ & $\{10,12,17,14\}$ & $(0.439,0,0.561,0,0,0)$ \\
\hline \multirow{3}{*}{ WA } & $\{18,23,25,29\}$ & $\{8,13,3,20\}$ & No solution \\
& OWA & $\{18,23,25,29\}$ & $\{13,14,9,20\}$ & No solution \\
& WA & $\{18,23,25,29\}$ & $\{17,23,24,28\}$ & $(0.124,0.165,0.043,0.107,0.561,0)$ \\
& OWA & $\{18,23,25,29\}$ & $\{14,22,23,24\}$ & $(0.06,0,0.32,0.332,0,0.288)$ \\
\hline
\end{tabular}

This illustrative example also highlights the main difference between the existing approaches to attribute weights setting and the proposed models in this study, which consists in the assumption made in the proposed model in this regarding the decision maker as dishonest, and aiming to find which the strategically setting of attribute weights to allow her/him to achieve the desired/targeted ranking of interest.

\subsection{Simulation experiments}

In MADM problems, the WA operator and the OWA operator are both frequently used to aggregate the associated attribute preference values to rank the alternatives. Therefore, a challenge for analysts is how to compare the performances of the WA and OWA operators in defending against the MADM strategic weight manipulation. In this subsection, we design simulation experiments to deal with this challenge.

Let $r_{w}^{W A}\left(x_{k}\right)$ and $r_{w}^{O W A}\left(x_{k}\right)$ be the rankings of $x_{k}$ under the attribute weight vector $w=\left(w_{1}, w_{2}, \ldots, w_{m}\right)$ when setting $F$ to be the WA and OWA operators, respectively. As stated previously, $r_{w}^{W A}\left(x_{k}\right)$ and $r_{w}^{O W A}\left(x_{k}\right)$ will vary for different weight vector $w=\left(w_{1}, w_{2}\right.$ $\left., \ldots, w_{m}\right)$. Next, we design simulation experiment I to show the fluctuation of both rankings of the alternatives as the attribute weight vector changes.

Simulation experiment I:

Step 1: We randomly generate a standardized decision matrix $\bar{V}=\left[\bar{v}_{i j}\right]_{50 \times 6}$, 
where $\bar{v}_{i j} \in[0,1]$.

Step 2: We randomly generate 1000 attribute weight vectors, $w_{i}=\left(w_{i, 1}, w_{i, 2}, \ldots, w_{i, m}\right.$ ) $(i=1,2, \ldots, 1000)$. Based on Eqs. (4) and (5), and the standardized decision matrix $\bar{V}=$ $\left[\bar{v}_{i j}\right]_{50 \times 6}$ obtained in Step 1. We obtain the ranking of alternative $x_{k}$ under the WA and OWA operators, $r_{w_{i}}^{W A}\left(x_{k}\right)$ and $r_{w_{i}}^{O W A}\left(x_{k}\right)(k=1,2, \ldots, 50 ; i=1,2, \ldots, 1000)$, respectively.

Figure 1 shows the average values of $r_{w_{i}}^{W A}\left(x_{k}\right)$ and $r_{w_{i}}^{O W A}\left(x_{k}\right)$ $(k \in\{6,12,20,35,46,50\} ; i=1,2, \ldots, 1000)$ in Simulation experiment I.
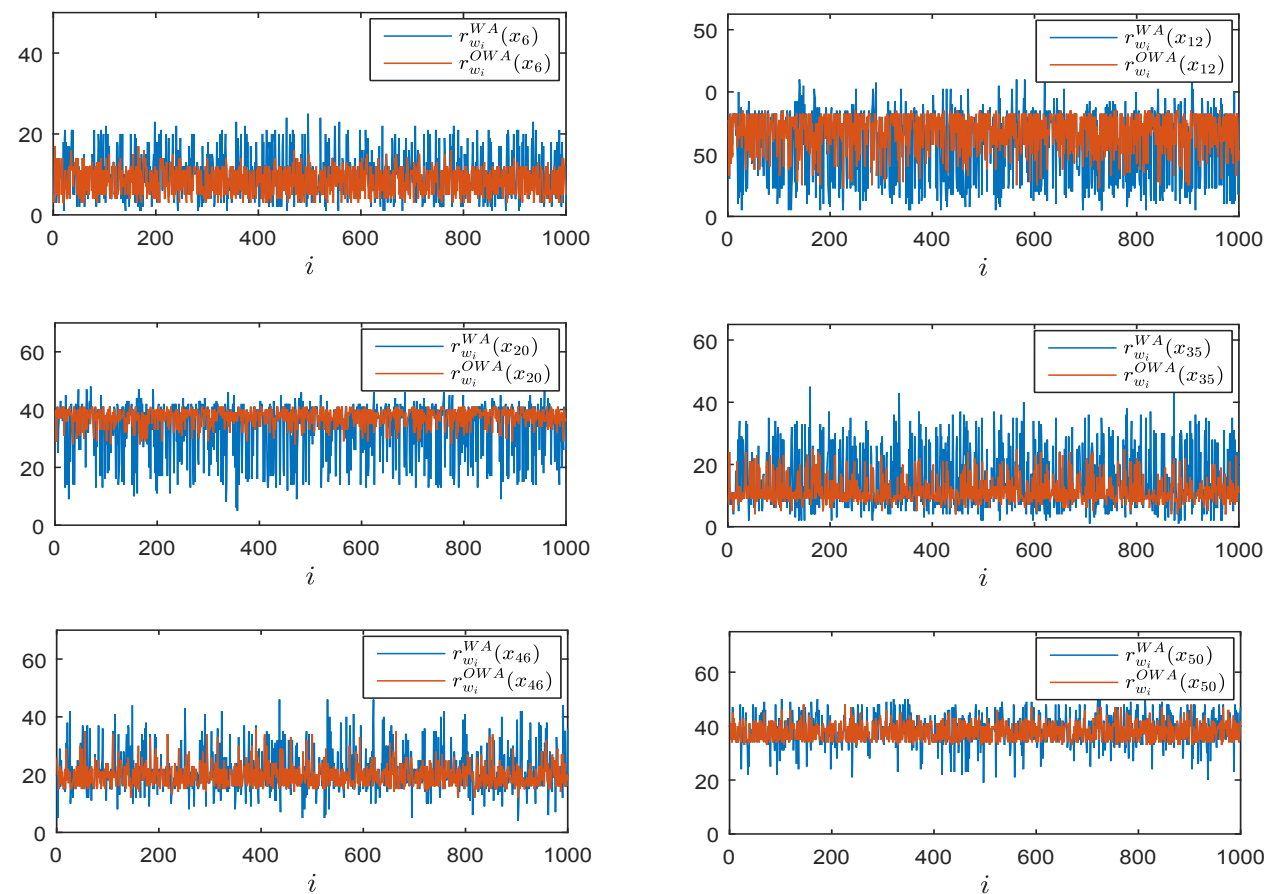

Figure 1: The average values of $r_{w_{i}}\left(x_{k}\right)$ for the alternatives under the WA and OWA operators.

Figure 1 clearly shows that the fluctuation of the rankings of the alternatives in the WA case is much larger than the rankings in the OWA case. Notably, we ran Simulation experiment I many times, and the obtained observations coincide. Generally, with the change of the attribute weight vector $w$, a larger fluctuation of the rankings of the alternatives implies a higher possibility to manipulate a strategic attribute weight vector to obtain a desired ranking. In other words, the larger the fluctuation of the rankings of the alternatives the worse performance in defending against strategic weight manipulation. 
Further, we use the ranking range of the alternative $x_{k}$ to measure the fluctuation degree of $r_{w}^{W A}\left(x_{k}\right)$ and $r_{w}^{O W A}\left(x_{k}\right)$. Let $R_{W A}=\left[\underline{r}_{W A}\left(x_{k}\right), \bar{r}_{W A}\left(x_{k}\right)\right]$ and $R_{O W A}=$ $\left[r_{O W A}\left(x_{k}\right), \bar{r}_{\text {OWA }}\left(x_{k}\right)\right]$ be as defined before in the paper.

Figure 2 shows the ranking range of the alternatives under the WA and OWA operators in the example presented in Section 5.1.

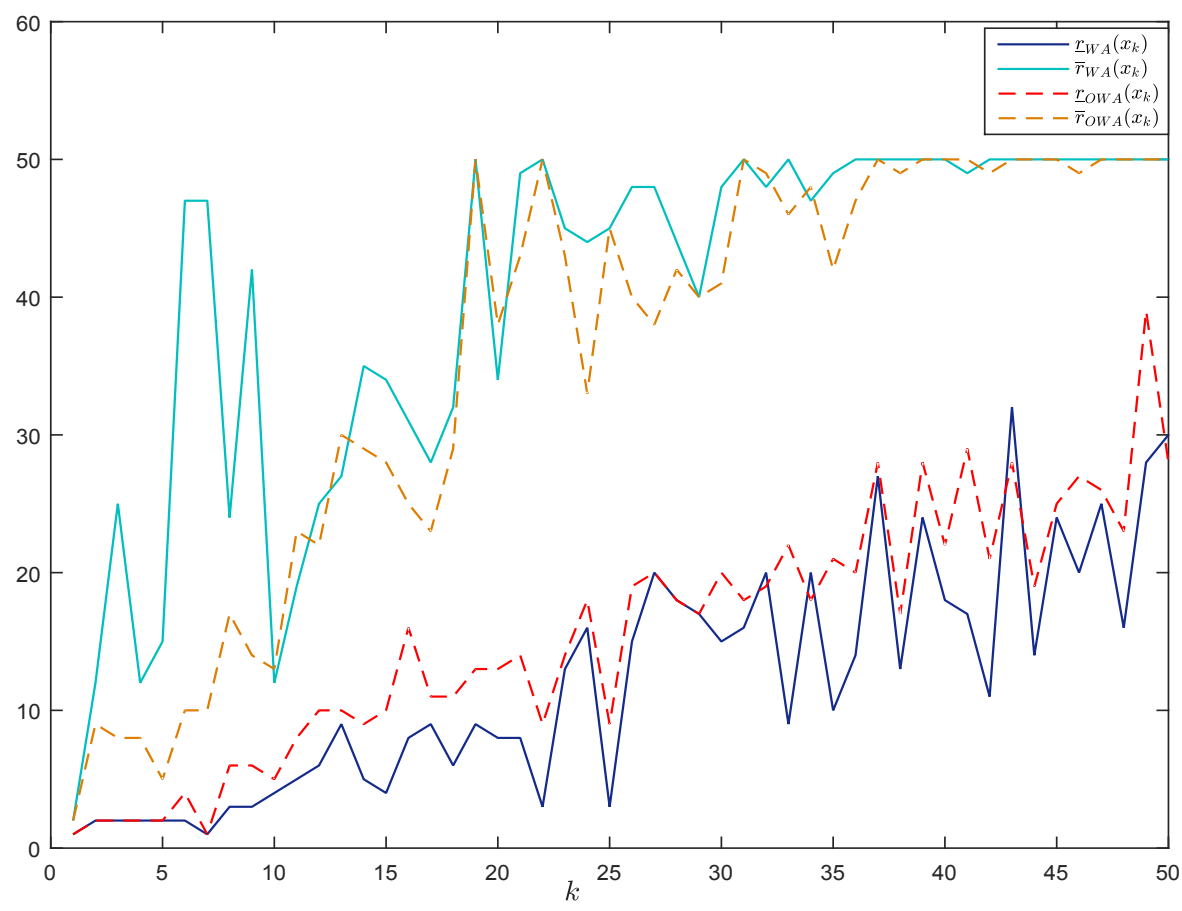

Figure 2: The ranking range of the alternatives in Example 5.1

A simulation experiment II is designed to analyse the average ranking range of the alternatives under the WA and OWA operators, respectively.

Simulation experiment II:

Step 1: We randomly generate an $n \times m$ standardized decision matrix $\bar{V}=\left[\bar{v}_{i j}\right]_{n \times m}$, with $\bar{v}_{i j} \in[0,1]$. Using model $P_{1}$, the ranking range of the alternative $x_{i},\left[\underline{r}_{W A}\left(x_{i}\right), \bar{r}_{W A}\left(x_{i}\right)\right]$, is computed, and using model $P_{2}$, the ranking range of the alternative $x_{i}$, $\left[\underline{r}_{\text {OWA }}\left(x_{i}\right), \bar{r}_{\text {OWA }}\left(x_{i}\right)\right]$, is computed as well. Let

$W R_{W A}\left(x_{i}\right)=\bar{r}_{W A}\left(x_{i}\right)-\underline{r}_{W A}\left(x_{i}\right)$

and

$$
W R_{O W A}\left(x_{i}\right)=\bar{r}_{O W A}\left(x_{i}\right)-\underline{r}_{O W A}\left(x_{i}\right)
$$

be the width of the ranking range of the alternative $x_{i}$ under the WA and OWA 
operators, respectively.

Step 2: When setting different $m$ and $n$, we run 100 times Step 1 to obtain the average values of $W R_{W A}\left(x_{i}\right)$ and $W R_{O W A}\left(x_{i}\right)$.

Figure 3 shows the average values of $W R_{W A}\left(x_{i}\right)$ and $W R_{O W A}\left(x_{i}\right)$ in Simulation experiment II.
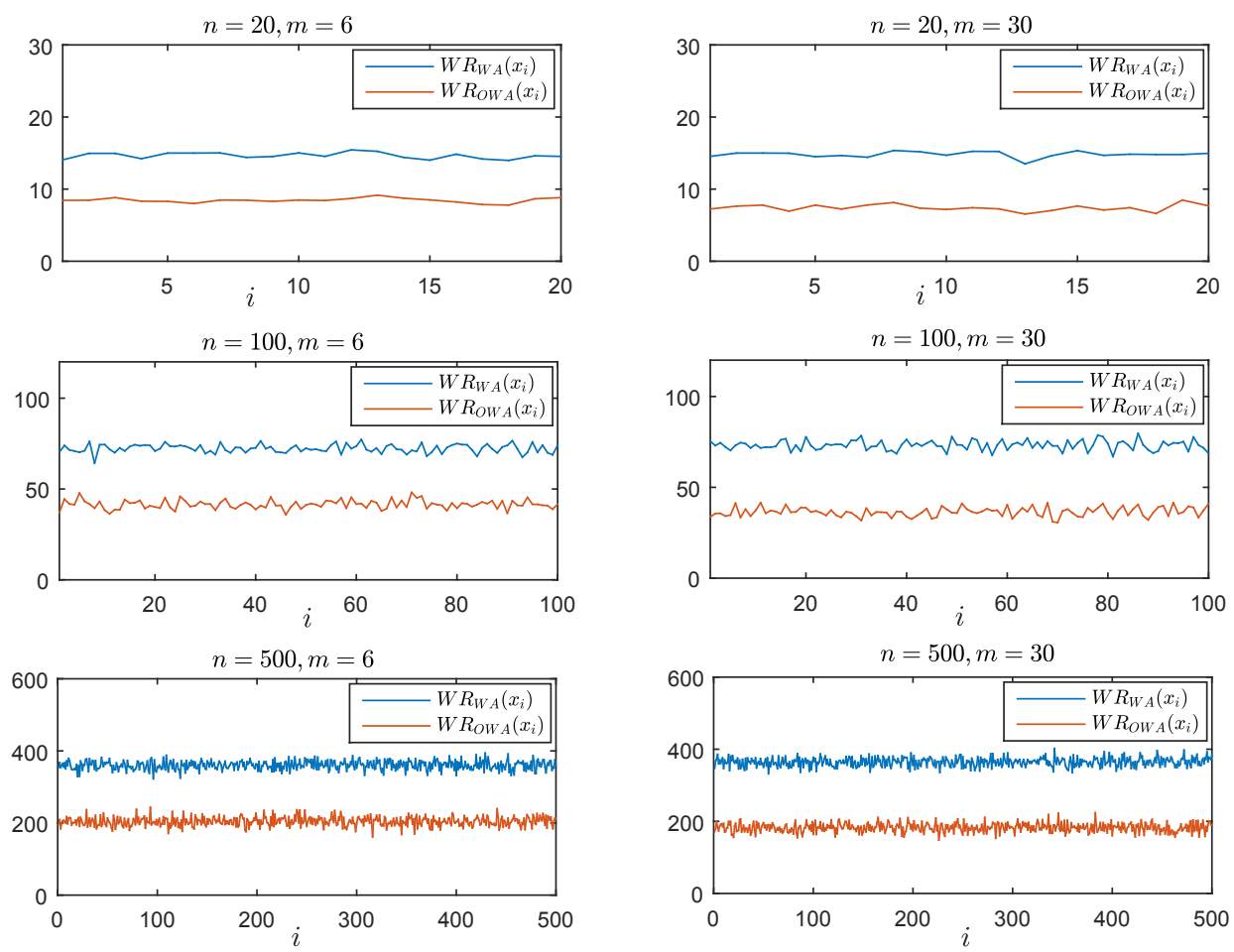

Figure 3: Average values of $W R\left(x_{i}\right)$ in simulation method II under the different

parameters.

From Figures 2 and 3, following observations are drawn:

(1) Figure 2 shows that $\left[r_{O W A}\left(x_{i}\right), \bar{r}_{O W A}\left(x_{i}\right)\right] \subseteq\left[r_{W A}\left(x_{i}\right), \bar{r}_{W A}\left(x_{i}\right)\right]$ in a vast majority of cases;

(2) Figure 3 shows the average width of the ranking range of the alternatives in the WA case is much larger than the ranking range in the OWA case.

Both observations show a better performance of the OWA operator than the WA operator in defending against strategic weight manipulation.

\section{Conclusions}

This paper focuses on some issues on the strategic attribute weight used to manipulate the ranking of alternatives. The main contributions presented are as 
follows:

(1) We define the concept of the ranking range of an alternative in the MADM framework, and propose MLPMs to obtain the ranking range of alternatives under the set of attribute weight $W$.

(2) We reveal the process of designing a strategic attribute weight vector, and analyze the conditions to manipulate a strategic attribute weight to obtain her/his desired ranking based on the ranking range and the proposed MLPMs.

(3) Simulation experiments are presented that show performance of the OWA operator exceeded that of the WA operator in defending against strategic weight manipulation in MADM problems.

In some MADM problems, a group of decision makers might be involved, and they could provide incomplete attribute weights information (e.g., [17, 19, 33]). In these instances, it will be an interesting future study to analyze the MADM strategic weight manipulation under a group context with incomplete attribute weights information. Other interesting proposal would be to analyze strategic weight manipulation in decision context under trust relationships [34, 35].

\section{Acknowledgments}

This work was supported by the grants (Nos.71171160 and 71571124) from NS F of China, the grants (No. skqy201606) from Sichuan University, the grants (Nos.TI N2013-40658-P and TIN2016-75850-R) from the FEDER funds, and the grant (No.TIC -5991) from the Andalusi-an Excellence Project.

\section{References}

[1] F.H. Barron, B.E. Barrett, Decision quality using ranked attribute weights, Management Science 42 (11) (1996) 1515-1523.

[2] P.A. Bottomley, J.R. Doyle, A comparison of three weight elicitation methods: good, better, and best, Omega 29 (6) (2001) 553-560.

[3] A. Charnes, W.W. Cooper, E. Rhodes, Measuring the efficiency of decision making units, European journal of operational research 2 (6) (1978) 429-444.

[4] W.D. Cook, M. Kress, A data envelopment model for aggregating preference rankings, Management Science 36 (11) (1990) 1302-1310. 
[5] M. Danielson, L. Ekenberg, Y. He, Augmenting ordinal methods of attribute weight approximation, Decision Analysis 11 (1) (2014) 21-26.

[6] Y.C. Dong, H.J. Zhang, E. Herrera-Viedma, Integrating experts' weights generated dynamically into the consensus reaching process and its applications in managing non-cooperative behaviors, Decision Support Systems 84 (2016) 115.

[7] Y.C. Dong, H.J. Zhang, E. Herrera-Viedma, Consensus reaching model in the complex and dynamic MAGDM problem, Knowledge-Based Systems 106 (2016) 206-219.

[8] J.R. Doyle, R.H. Green, P.A. Bottomley, Judging relative importance: direct rating and point allocation are not equivalent, Organizational Behavior and Human Decision Processes 70 (1) (1997) 65-72.

[9] I.N. Durbach, T.J. Stewart, Modeling uncertainty in multi-criteria decision analysis, European Journal of Operational Research 223 (1) (2012) 1-14.

[10] C.A.B. e Costa, M.D. Oliveira, A multicriteria decision analysis model for faculty evaluation, Omega 40 (4) (2012) 424-436.

[11] Z.P. Fan, J. Ma, Q. Zhang, An approach to multiple attribute decision making based on fuzzy preference information on alternatives, Fuzzy sets and systems 131 (1) (2002) 101-106.

[12] J. Geldermann, V. Bertsch, M. Treitz, S. French, K.N. Papamichail, R.P. Hämäläinen, Multi-criteria decision support and evaluation of strategies for nuclear remediation management, Omega 37 (1) (2009) 238-251.

[13] Z.W. Gong, X.X. Xu, H.H. Zhang, E. Herrera-Viedma, The consensus models with interval preference opinions and their economic interpretation, Omega 2015 (55) (2015) 81-90.

[14] D. Horsky, M.R. Rao, Estimation of attribute weights from preference comparisons, Management Science 30 (7) (1984) 801-822.

[15] A. Ishizaka, P. Nemery, Multi-criteria decision analysis: methods and software, John Wiley \& Sons 2013.

[16] M. Kadziński, S. Greco, R. Słowiński, RUTA: a framework for assessing and 
selecting additive value functions on the basis of rank related requirements, Omega 41 (4) (2013) 735-751.

[17] W.Q. Liu, Y.C. Dong, F. Chiclana, F.J. Cabrerizo, E. Herrera-Viedma, Group decision-making based on heterogeneous preference relations with selfconfidence, Fuzzy Optimization and Decision Making, in press, DOI $10.1007 / \mathrm{s} 10700-016-9254-8$.

[18] J.C. Lourenco, A. Morton, C.A.B. e Carlos, PROBE-a multicriteria decision support system for portfolio robustness evaluation, Decision support systems 54 (1) (2012) 534-550.

[19] A. Mateos, A. Jiménez, S. Ríos-Insua, Monte Carlo simulation techniques for group decision making with incomplete information, European Journal of Operational Research 174 (3) (2006) 1842-1864.

[20] C.S. McCahon, C.L. Hwang, F.A. Tillman, A multiple attribute evaluation of Bayesian availability estimators, IEEE transactions on reliability 32 (5) (1983) 496-503.

[21] I. Palomares, L. Martínez, F. Herrera, A consensus model to detect and manage noncooperative behaviors in large-scale group decision making, IEEE Transactions on Fuzzy Systems 22 (3) (2014) 516-530.

[22] J. Pang, J. Liang, Evaluation of the results of multi-attribute group decisionmaking with linguistic information, Omega 40 (3) (2012) 294-301.

[23] D. Pekelman, S.K. Sen, Mathematical programming models for the determination of attribute weights, Management Science 20 (8) (1974) 12171229.

[24] D.A. Pelta, R.R. Yager, Decision strategies in mediated multiagent negotiations: an optimization approach, IEEE Transactions on Systems, Man, and Cybernetics Part A: Systems and Humans 40 (3) (2010) 635-640.

[25] J. Rezaei, Best-worst multi-criteria decision-making method, Omega 53 (2015) 49-57.

[26] R. Roberts, P. Goodwin, Weight approximations in multi-attribute decision models, Journal of Multi-Criteria Decision Analysis 11 (6) (2002) 291-303. 
[27] Shanghai Jiao Tong University, Academic Ranking of World Universities, http://www.arwu.org / 2015-8-15.

[28] L.E. Shirland, R.R. Jesse, R.L. Thompson, C.L. Iacovou, Determining attribute weights using mathematical programming, Omega 31 (6) (2003) 423-437.

[29] W.G. Stillwell, D.A. Seaver, W. Edwards, A comparison of weight approximation techniques in multiattribute utility decision making, Organizational Behavior and Human Performance 28 (1) (1981) 62-77.

[30] B.Z. Sun, W.M. Ma, An approach to consensus measurement of linguistic preference relations in multi-attribute group decision making and application, Omega 51 (2015) 83-92.

[31] J. Wallenius, J.S. Dyer, P.C. Fishburn, R.E. Steuer, S. Zionts, K. Deb, Multiple criteria decision making, multiattribute utility theory: Recent accomplishments and what lies ahead, Management Science 54 (7) (2008) 1336-1349.

[32] Y.M. Wang, K.S. Chin, The use of OWA operator weights for cross-efficiency aggregation, Omega 39 (5) (2011) 493-503.

[33] M. Weber, A method of multiattribute decision making with incomplete information, Management Science 31 (11) (1985) 1365-1371.

[34] J. Wu, F. Chiclana, E. Herrera-Viedma, Trust based consensus model for social network in an incomplete linguistic information context, Applied Soft Computing 35 (2015) 827-839.

[35] J. Wu, F. Chiclana, A social network analysis trust-consensus based approach to group decision-making problems with interval-valued fuzzy reciprocal preference relations, Knowledge-Based Systems, 59 (2014) 97-107.

[36] X.H. Xu, Z.J. Du, X.H. Chen, Consensus model for multi-criteria large-group emergency decision making considering non-cooperative behaviors and minority opinions, Decision Support Systems 79 (2015) 150-160.

[37] R.R. Yager, Defending against strategic manipulation in uninorm-based multiagent decision making, European Journal of Operational Research 141 (1) (2002) $217-232$.

[38] R.R. Yager, Penalizing strategic preference manipulation in multi-agent decision 
making, IEEE Transactions on Fuzzy Systems 9 (3) (2001) 393-403.

[39] R.R. Yager, On ordered weighted averaging aggregation operators in multicriteria decision making, IEEE Transactions on Systems, Man, and Cybernetics 18 (1) (1988) 183-190.

[40] K. Yoon, C.L. Hwang, Multiple attribute decision making: methods and applications, Springer, Berlin 1981

[41] S.H. Zanakis, A. Solomon, N. Wishart, S. Dublish, Multi-attribute decision making: A simulation comparison of select methods, European journal of operational research 107 (3) (1998) 507-529.

\section{Appendix A: Proofs.}

\section{Proof of Theorem 1:}

The process of proving Theorem 1 is divided into two steps.

Step 1: On the one hand, using WA operator as per Eq. (4), based on the constraints (9)-(13) and result (1), i.e., $x_{i}>x_{k}$ if and only if $y_{i}=1$ under the conditions $D\left(x_{i}\right)>D\left(x_{k}\right)-\left(1-y_{i}\right) M$ and $D\left(x_{i}\right) \leq D\left(x_{k}\right)+y_{i} M$, we can obtain,

$$
\begin{aligned}
& \underline{r}\left(x_{k}\right)=1+\min \left|\left\{x_{i} \mid D\left(x_{i}\right)>D\left(x_{k}\right), \quad i=1,2, \ldots, n\right\}\right|
\end{aligned}
$$

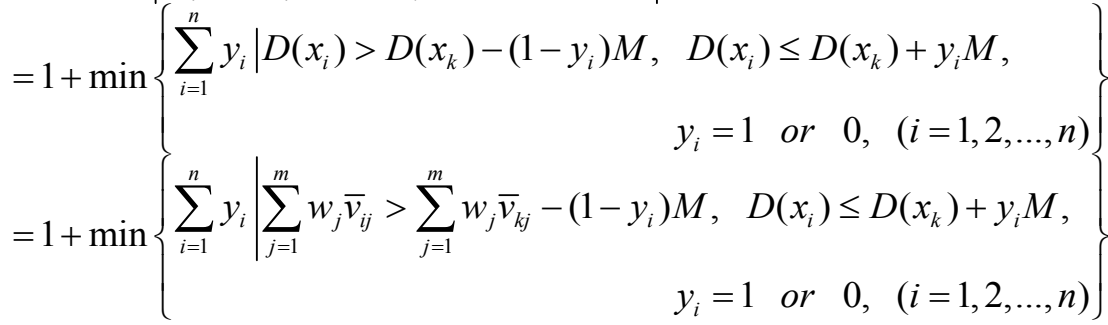

$$
\begin{aligned}
& =1+\min \sum_{i=1}^{n} y_{i}, \quad(i=1,2, \ldots, n)
\end{aligned}
$$

where $M$ is a large enough number.

On the other hand, using WA operator as per Eq. (4), $\sum_{j=1}^{m} w_{j} \bar{v}_{i j} \leq \sum_{j=1}^{m} w_{j} \bar{v}_{k j}+y_{i} M$, $\sum_{j=1}^{m} w_{j} \bar{v}_{i j}>\sum_{j=1}^{m} w_{j} \bar{v}_{k j}-\left(1-y_{i}\right) M$ when $y_{i}=0$, based on result (2), i.e., $x_{i} \preccurlyeq x_{k}$ if and only if $y_{i}=0$ under the conditions $D\left(x_{i}\right) \leq D\left(x_{k}\right)+y_{i} M$ and $D\left(x_{i}\right)>D\left(x_{k}\right)-\left(1-y_{i}\right) M$. Then, according to the definition of ranking of the alternatives and Eq. (6), we have $\underline{r}$ $\left(x_{k}\right)=1+\min \sum_{i=1}^{n} y_{i}$.

Step 2: On the one hand, based on the constraints (9)-(13) and result (1) in step 1, we can obtain, 


$$
\begin{aligned}
& \bar{r}\left(x_{k}\right)=1+\max \left|\left\{x_{i} \mid D\left(x_{i}\right)>D\left(x_{k}\right)\right\}\right| \\
& =1+\max \left\{\begin{array}{r}
\sum_{i=1}^{n} y_{i} \mid D\left(x_{i}\right)>D\left(x_{k}\right)-\left(1-y_{i}\right) M, \\
=1+\max \left\{\sum_{i=1}\right) \leq D\left(x_{k}\right)+y_{i} M, \\
y_{i}=1 \text { or } 0,(i=1,2, \ldots, n)
\end{array}\right\} \\
& =1+\max \sum_{i=1}^{n} y_{i}, \quad(i=1,2, \ldots, n)
\end{aligned}
$$

where $M$ is a large enough number.

On the other hand, the proof of is similar to the proof of step 1.

Above all, this completes the proof of Theorem 1.

\section{Proof of Theorem 2:}

The proof of Theorem 2 is similar to the proof of Theorem 1. Here, we only replace the WA operator $D\left(x_{i}\right)=\sum_{j=1}^{m} w_{j} \bar{v}_{i j}$ and $D\left(x_{k}\right)=\sum_{j=1}^{m} w_{j} \bar{v}_{k j}$ by OWA operator $D\left(x_{i}\right)=\sum_{j=1}^{m} w_{j} \bar{v}_{i(j)}$ and $D\left(x_{k}\right)=\sum_{j=1}^{m} w_{j} \bar{v}_{k(j)}$ in proof of Theorem 1.

Then, this completes the proof of Theorem 2 .

\section{Proof of Property 1:}

The proof of Property 1 required proving that given alternative $x_{k}$, if its attribute ranking verifies $c_{j}\left(x_{k}\right) \in\left[\underline{c}\left(x_{k}\right), \bar{c}\left(x_{k}\right)\right]$, then it is also $c_{j}\left(x_{k}\right) \in\left[\underline{r}_{W A}\left(x_{k}\right), \bar{r}_{W A}\left(x_{k}\right)\right]$.

Let $c_{j}\left(x_{k}\right)$ be the attribute ranking of alternative $x_{k}$ associated with attribute $a_{j}$ and

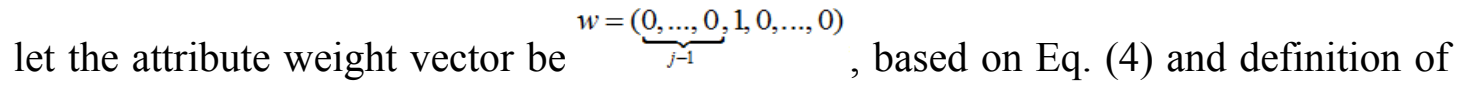
ranking of alternative, we have that $r_{W A}\left(x_{k}\right)=c_{j}\left(x_{k}\right)$, i.e., $r_{W A}\left(x_{k}\right) \in\left[\underline{r}_{W A}\left(x_{k}\right), \bar{r}_{W A}\left(x_{k}\right)\right]$.

This completes the proof of property 1 .

\section{Proof of Property 2:}

(i) We firstly prove that the best ranking of alternative $x_{k}, \underline{r}_{W A}\left(x_{k}\right)$, satisfies $\underline{r}_{W A}$ $\left(x_{k}\right) \in\left[\left|O_{I_{k}}\left(x_{k}\right)\right|+1, \underline{c}\left(x_{k}\right)\right]$.

On the one hand, let $O_{I_{k}}\left(x_{k}\right)=\left\{x_{i} \mid \bar{v}_{i j}>\bar{v}_{k j}, j=1,2, \ldots, m\right\}$ be as previously defined, and $\left|\bar{O}_{I_{k}}\left(x_{k}\right)\right|$ be number of alternatives $x_{h}$, satisfying $x_{h} \in O_{I_{k}}\left(x_{k}\right)$. Using the WA operator as per Eq. (4), we obtain, 


$$
D\left(x_{h}\right)-D\left(x_{k}\right)=\sum_{j=1}^{m} w_{j} \bar{v}_{h j}-\sum_{j=1}^{m} w_{j} \bar{v}_{k j}=\sum_{j=1}^{m} w_{j}\left(\bar{v}_{h j}-\bar{v}_{k j}\right)>0 .
$$

According to the definition of ranking of alternatives, we obtain $\left|O_{I_{k}}\left(x_{k}\right)\right|+1 \leq$ $\underline{r}_{W A}\left(x_{k}\right)$.

On the other hand, based on property 1 , it is obvious that the best ranking of the alternative $x_{k}, \underline{r}_{W A}\left(x_{k}\right)$, satisfies $\underline{r}_{W A}\left(x_{k}\right) \leq \underline{c}\left(x_{k}\right)$.

(ii) We further prove that the worst ranking of the alternative $x_{k}, \bar{r}_{W A}\left(x_{k}\right)$, satisfies $\bar{r}_{W A}\left(x_{k}\right) \in\left[\bar{c}\left(x_{k}\right), n-\left|\bar{O}_{I_{k}}\left(x_{k}\right)\right|\right]$.

On the one hand, let $\bar{O}_{I_{k}}\left(x_{k}\right)=\left\{x_{i} \mid \bar{v}_{i j} \leq \bar{v}_{k j}, j=1,2, \ldots, m\right\}$ be as previously defined, and $\left|\bar{O}_{I_{k}}\left(x_{k}\right)\right|$ be the number of alternatives $x_{h}$, satisfying $x_{h} \in \bar{O}_{I_{k}}\left(x_{k}\right)$, then there exist at most $n-\left|\bar{O}_{I_{k}}\left(x_{k}\right)\right|-1$ alternatives $x_{f}$ satisfying $x_{f} \in O_{I_{k}}\left(x_{k}\right)$, according to the process of proof in (i), we obtain $\bar{r}_{W A}\left(x_{k}\right) \leq n-\left|\bar{O}_{I_{k}}\left(x_{k}\right)\right|$.

On the other hand, based on property 1 , it is obvious that the worst ranking of the alternative $x_{k}$, satisfies $\bar{r}_{W A}\left(x_{k}\right) \geq \bar{c}\left(x_{k}\right)$.

This completes the proof of property 2 .

\section{Proof of Lemma 1:}

(1) Because $w^{*}=\left(w_{1}^{*}, w_{2}^{*}, \ldots, w_{m}^{*}\right)$ satisfies the constraints (25)-(30), then it is:

$$
\left\{\begin{array}{l}
\sum_{j=1}^{m} w_{j}^{*} \bar{v}_{i j}>\sum_{j=1}^{m} w_{j}^{*} \bar{v}_{k j}-\left(1-y_{i k}\right) M, \quad(i=1,2, \ldots, n ; k=1,2, \ldots, l) \\
\sum_{j=1}^{m} w_{j}^{*} \bar{v}_{i j} \leq \sum_{j=1}^{m} w_{j}^{*} \bar{v}_{k j}+y_{i k} M, \quad(i=1,2, \ldots, n ; k=1,2, \ldots, l) \\
\sum_{i=1}^{n} y_{i k}+1=r^{*}\left(x_{k}\right), \quad(i=1,2, \ldots, n ; \quad k=1,2, \ldots, l) \\
\sum_{j=1}^{m} w_{j}^{*}=1 \\
0 \leq w_{j}^{*} \leq 1, \quad(j=1,2, \ldots, m) \\
y_{i k}=1 \quad \text { or } \quad 0, \quad(i=1,2, \ldots, n ; k=1,2, \ldots, l)
\end{array}\right.
$$

We have $\sum_{j=1}^{m} w_{j}^{*} \bar{v}_{i j}>\sum_{j=1}^{m} w_{j}^{*} \bar{v}_{k j}(k=1,2, \ldots, l)$ and $\sum_{j=1}^{m} w_{j}^{*} \bar{v}_{i j} \leq \sum_{j=1}^{m} w_{j}^{*} \bar{v}_{k j}+1 \cdot M$, $k=1,2, \ldots, l)$ when $y_{i k}=1$, based on result (1) in proof of Lemma 1, we have $x_{i}>x_{k}$ 
$(k=1,2, \ldots, l)$. And, when $y_{i k}=0, \sum_{j=1}^{m} w_{j}^{*} \bar{v}_{i j} \leq \sum_{j=1}^{m} w_{j}^{*} \bar{v}_{k j},(k=1,2, \ldots, l)$ and $\sum_{j=1}^{m} w_{j}^{*} \bar{v}_{i j}>$ $\sum_{j=1}^{m} w_{j}^{*} \bar{v}_{k j}-1 \cdot M,(k=1,2, \ldots, l)$, based on result (2) in proof of Lemma 1, we have $x_{i} \preccurlyeq x_{k}$ $(k=1,2, \ldots, l)$. Based on the condition $\sum_{i=1}^{m} y_{i k}+1=r^{*}\left(x_{k}\right)(i=1,2, \ldots, n ; k=1,2, \ldots, l)$ and the definition of ranking of alternative, we obtain $r_{w^{*}}\left(x_{k}\right)=r^{*}\left(x_{k}\right)(k=1,2, \ldots, l)$.

This completes the proof of Lemma 1.

\section{Proof of Lemma 2:}

The proof of Lemma 2 is similar to the proof of Lemma 1. Here, we only replace the WA operator $D\left(x_{i}\right)=\sum_{j=1}^{m} w_{j} \bar{v}_{i j}$ and $D\left(x_{k}\right)=\sum_{j=1}^{m} w_{j} \bar{v}_{k j}$ by the OWA operator $D\left(x_{i}\right)=$ $\sum_{j=1}^{m} w_{j} \bar{v}_{i(j)}$ and $D\left(x_{k}\right)=\sum_{j=1}^{m} w_{j} \bar{v}_{k(j)}$ in proof of Lemma 1 to obtain $r_{w^{*}}\left(x_{k}\right)=r^{*}\left(x_{k}\right)($ $k=1,2, \ldots, l)$.

This completes the proof of Lemma 2.

\section{Proof of Theorem 3:}

Introducing the following two transformed decision variables $b_{j}=w_{j}-w_{j}^{0}$ and $g_{j}$ $=\left|w_{j}-w_{j}^{0}\right|$, it is $b_{j} \leq g_{j}$ and $-b_{j} \leq g_{j}$, which guarantee $g_{j} \geq\left|b_{j}\right|=\left|w_{j}-w_{j}^{0}\right|$.

Based on Lemmas 1 and 2, put models (25)-(30) and (27)-(32) into Eq. (24), then the Eq. (24) can be transformed into mixed 0-1 linear programming models (33)(42) and (35)-(44).

This completes the proof of Theorem 3.

\section{Proof of Property 3:}

First, we prove the existence of solution to model $P_{3}$ as follows.

Let $r_{w_{0}}=\left\{r_{w_{0}}\left(x_{1}\right), r_{w_{0}}\left(x_{2}\right), \ldots, r_{w_{0}}\left(x_{l}\right)\right\}$ be the objective ranking of the alternatives $\left\{x_{1}\right.$, $\left.x_{2}, \ldots, x_{l}\right\}$, let $r^{*}=\left\{r^{*}\left(x_{1}\right), r^{*}\left(x_{2}\right), \ldots, r^{*}\left(x_{l}\right)\right\}$ be the decision maker's desired rankings of the alternatives $\left\{x_{1}, x_{2}, \ldots, x_{l}\right\}$, and we have $r^{*}\left(x_{k}\right) \in\left[\underline{r}_{W A}\left(x_{k}\right), \bar{r}_{W A}\left(x_{k}\right)\right](k=1,2, \ldots, l)$. Based on the continuous of ranking range, using enumeration, let the ranking of alternatives be $\quad r^{*}=\left\{r_{w_{0}}\left(x_{1}\right)-1, r_{w_{0}}\left(x_{2}\right), \ldots, r_{w_{0}}\left(x_{l}\right)\right\},\left\{r_{w_{0}}\left(x_{1}\right), r_{w_{0}}\left(x_{2}\right)-1, \ldots, r_{w_{0}}\left(x_{l}\right)\right\}, \ldots,\left\{r_{w_{0}}\left(x_{1}\right), r_{w_{0}}\left(x_{2}\right.\right.$ ),.., $\left.r_{w_{0}}\left(x_{l}\right)-1\right\}$, respectively. Then, there must exist $r^{*}$, the feasible solution of model 
$P_{3}$ exists; otherwise, the objective ranking $r_{w_{0}}$ is the best ranking of alternatives, which contradicts the assumption in the beginning. Then, we can prove that model $P_{3}$ has feasible solution.

Similarly, we can prove the model $P_{4}$ has feasible solution.

This completes the proof of Property 3.

\section{Proof of Property 4:}

According to the conditions in Property 4, without loss of generality, let $r^{*}=\left\{\underline{r}\left(x_{1}\right), \ldots, \underline{r}\left(x_{l}\right)\right\}=\{\underline{r}\left(x_{1}\right), \ldots, \underbrace{r\left(x_{h-b-1}\right)=\underline{r}\left(x_{k}\right), \ldots, \underline{r}\left(x_{h-1}\right)=\underline{r}\left(x_{k}\right)}_{b+1}, \underline{r}\left(x_{h}\right), \ldots, \underline{r}\left(x_{l}\right)\}$ be our desired ranking of the alternatives $\left\{x_{1}, x_{2}, \ldots, x_{l}\right\}$, let $r^{*}$ be denoted as monotonically increasing, then, we have $\underline{r}\left(x_{h}\right)=\underline{r}\left(x_{k}\right)+b+1$, which contradict the condition $\underline{r}\left(x_{k}\right)<\underline{r}\left(x_{h}\right)<\underline{r}\left(x_{k}\right.$ )$+b$ in Property 4 .

This completes the proof of Property 4.

\section{Proof of Property 5:}

We prove the Property 5 with reduction to absurdity as follows.

When $l=1$, we assume that model $P_{3}$ has no solution for ranking $r\left(x_{k}\right)$, which satisfies $r\left(x_{k}\right) \in\left[\underline{r}_{W A}\left(x_{k}\right), \bar{r}_{W A}\left(x_{k}\right)\right]$, then, there is no attribute weights $w$ such that the alternative $x_{k}$ can obtain the ranking $r_{w}\left(x_{k}\right)$, which contradicts the continuous of ranking range, so we obtain that the solution of model $P_{3}$ exists.

Similarly, we can prove the existence of solution to model $P_{4}$.

This completes the proof of Property 5.

\section{Appendix B: The original data for 50 universities in Section 5.1}

\begin{tabular}{ccccccc}
\hline$x_{i}$ & $\bar{v}_{i 1}$ & $\bar{v}_{i 2}$ & $\bar{v}_{i 3}$ & $\bar{v}_{i 4}$ & $\bar{v}_{i 5}$ & $\bar{v}_{i 6}$ \\
\hline 1 & 100 & 100.0 & 100 & 100 & 100 & 76.6 \\
2 & 40.7 & 89.6 & 80.1 & 70.1 & 70.6 & 53.8 \\
3 & 68.2 & 80.7 & 60.6 & 73.1 & 61.1 & 68.0 \\
4 & 65.1 & 79.4 & 66.1 & 65.6 & 67.9 & 56.5 \\
5 & 77.1 & 96.6 & 50.8 & 55.6 & 66.4 & 55.8 \\
6 & 53.3 & 93.4 & 57.1 & 43.0 & 42.4 & 70.3 \\
7 & 49.5 & 66.7 & 49.3 & 56.4 & 44.0 & 100.0 \\
8 & 63.5 & 65.9 & 52.1 & 51.9 & 68.8 & 33.2 \\
9 & 59.8 & 86.3 & 49.0 & 42.9 & 49.8 & 42.0 \\
10 & 49.7 & 54.9 & 52.3 & 51.9 & 70.9 & 43.1 \\
11 & 47.6 & 50.4 & 51.0 & 58.8 & 63.0 & 37.8 \\
\hline
\end{tabular}




\begin{tabular}{|c|c|c|c|c|c|c|}
\hline 12 & 29.5 & 47.1 & 52.3 & 47.2 & 70.7 & 31.6 \\
\hline 13 & 42.0 & 49.8 & 50.4 & 45.3 & 59.9 & 40.2 \\
\hline 14 & 19.2 & 35.5 & 56.6 & 55.1 & 62.9 & 36.6 \\
\hline 15 & 21.2 & 31.6 & 53.0 & 51.7 & 71.9 & 29.3 \\
\hline 16 & 37.7 & 33.6 & 44.0 & 44.9 & 70.2 & 28.8 \\
\hline 17 & 31.6 & 33.8 & 49.6 & 39.6 & 67.7 & 37.4 \\
\hline 18 & 28.1 & 36.2 & 38.5 & 40.6 & 71.7 & 32.7 \\
\hline 19 & 0.0 & 39.9 & 46.8 & 53.5 & 59.5 & 34.9 \\
\hline 20 & 29.5 & 35.5 & 38.4 & 45.9 & 55.7 & 46.3 \\
\hline 21 & 30.8 & 14.1 & 41.9 & 48.6 & 70.8 & 28.8 \\
\hline 22 & 34.4 & 0.0 & 56.2 & 41.3 & 75.9 & 25.6 \\
\hline 23 & 14.5 & 35.8 & 44.2 & 34.5 & 62.0 & 38.0 \\
\hline 24 & 30.8 & 34.8 & 40.2 & 35.7 & 62.5 & 24.6 \\
\hline 25 & 19.9 & 17.2 & 38.8 & 38.6 & 79.1 & 29.3 \\
\hline 26 & 31.6 & 37.2 & 33.6 & 32.6 & 59.0 & 23.5 \\
\hline 27 & 28.1 & 31.9 & 35.2 & 40.3 & 56.2 & 23.3 \\
\hline 28 & 15.4 & 22.1 & 50.3 & 37.0 & 58.1 & 28.8 \\
\hline 29 & 29.9 & 36.2 & 34.9 & 32.4 & 55.5 & 28.6 \\
\hline 30 & 29.5 & 16.3 & 47.3 & 32.5 & 64.0 & 26.2 \\
\hline 31 & 15.4 & 14.9 & 50.2 & 39.0 & 61.7 & 23.9 \\
\hline 32 & 22.9 & 24.9 & 40.7 & 41.8 & 50.5 & 26.0 \\
\hline 33 & 17.0 & 59.8 & 30.3 & 40.9 & 19.0 & 39.6 \\
\hline 34 & 12.6 & 34.1 & 37.1 & 36.0 & 45.0 & 34.2 \\
\hline 35 & 21.8 & 18.8 & 28.0 & 34.0 & 63.2 & 39.2 \\
\hline 36 & 33.6 & 27.4 & 25.8 & 29.8 & 59.2 & 23.9 \\
\hline 37 & 16.2 & 16.3 & 38.6 & 37.5 & 56.0 & 26.6 \\
\hline 38 & 14.5 & 39.1 & 38.7 & 27.5 & 37.3 & 38.0 \\
\hline 39 & 8.9 & 16.3 & 39.8 & 33.5 & 61.2 & 25.6 \\
\hline 40 & 15.4 & 18.8 & 32.8 & 32.0 & 63.0 & 24.2 \\
\hline 41 & 18.5 & 32.6 & 27.1 & 26.1 & 56.2 & 25.6 \\
\hline 42 & 30.3 & 54.3 & 16.8 & 17.4 & 47.3 & 26.6 \\
\hline 43 & 19.2 & 20.0 & 33.0 & 31.6 & 52.7 & 26.5 \\
\hline 44 & 17.0 & 13.3 & 28.6 & 25.3 & 66.9 & 30.2 \\
\hline 45 & 18.5 & 34.5 & 31.1 & 35.6 & 35.8 & 22.4 \\
\hline 46 & 19.9 & 25.3 & 23.7 & 29.4 & 51.7 & 34.2 \\
\hline 47 & 20.5 & 24.9 & 25.8 & 30.5 & 51.9 & 25.9 \\
\hline 48 & 22.4 & 26.6 & 24.8 & 23.5 & 50.8 & 37.4 \\
\hline 49 & 0.0 & 31.7 & 35.6 & 22.1 & 53.2 & 20.3 \\
\hline 50 & 0.0 & 29.3 & 34.3 & 28.9 & 45.3 & 27.5 \\
\hline
\end{tabular}

